CITATION: DOI: http://dx.doi.org/10.12968/ijtr.2015.22.6.289 International Journal of Therapy and Rehabilitation.

V Booth1, P Logan1, R Harwood2, V Hood3

${ }^{1}$ Division of Rehabilitation and Aging, University of Nottingham

${ }^{2}$ Nottingham University Hospitals NHS Trust

${ }^{3}$ Physiotherapy and Rehabilitation Sciences, University of Nottingham

Received: March 18, 2015, Accepted: March 30, 2015, Published Online: June 04, 2015

\title{
Falls Prevention Interventions in Older Adults with a Cognitive Impairment: A Critical Review of Reviews
}

\section{Authors:}

Miss Vicky Booth ${ }^{1}$

Professor Pip Logan ${ }^{1}$

Professor Rowan Harwood ${ }^{2}$

Dr Victoria Hood ${ }^{3}$

${ }^{1}$ Division of Rehabilitation and Aging, University of Nottingham

${ }^{2}$ Nottingham University Hospitals NHS Trust

${ }^{3}$ Physiotherapy and Rehabilitation Sciences, University of Nottingham

\section{Correspondence to:}

Miss Vicky Booth, Division of Rehabilitation and Aging, B101 B Floor School of Medicine, University of Nottingham, NG7 2UH mcxvb2@nottingham.ac.uk 


\section{Abstract}

Aim: This critical review explores the review material on falls prevention interventions in older adults with a cognitive impairment such as dementia.

Method: A critical, systematic, review of review method was used. Five large electronic databases, MEDLINE, EMBASE, AMED, CINAHL, and the Cochrane electronic library, were searched. The search terms 'falls', 'rehabilitation', 'falls prevention', 'interventions', 'cognitive impairment', 'dementia', and 'Alzheimer's disease', were used. All available reviews were marked against predetermined inclusion and exclusion criteria.

Results: There were seven reviews which met the inclusion criteria. Only one of the included reviews had a homogenous population of adults with a cognitive impairment. Exercise was the most commonly reported intervention, included in 91 studies and all seven reviews. Multifactorial and multicomponent falls prevention programmes were also frequently reported. Reports of efficacy were inconsistent for all interventions.

Conclusion: Evidence for falls prevention interventions for adults with cognitive impairment is varied and inconclusive. When compared to literature for falls interventions in healthy older adults, both primary and synthesis studies in older adults with cognitive impairment are lacking in quality, number and homogeneity of sample population and interventions. Promising results are emerging but clinical recommendations cannot be made at this time.

Keywords: cognitive impairment, dementia, falls, fall interventions, critical review

\section{Introduction}

Dementia is a global and irreversible loss of cognitive abilities accompanied by a reduced ability to perform activities of daily living and a variety of neuropsychiatric symptoms (Dening and Thomas 2013). By 2021 there will be over one million people in the UK with dementia (Alzheimer's-Society 2014). As the proportion of older adults in our population increases, issues regarding falls and dementia will become more prevalent. Older adults with dementia have double the risk of falling compared with age matched individuals, with $60 \%-80 \%$ of people with dementia falling within a year (Shaw, Bond et al. 2003, Lord, Sherrington et al. 2007, Delbaere, Kochan et al. 2012). The economic impact on health services from falls in this population is considerable, with an estimated financial cost to the UK of over $£ 23$ billion (Craig, Murray et al. 2013).

Dementia encompasses a group of neurodegenerative disorders and the term cognitive impairment is correspondingly used to describe the reduced cognitive 
function or processes an individual with dementia or other neurological conditions may encounter. Cognition plays a crucial role in the control of gait. Gait is controlled by a complex neuronal network of ascending information, cortical involvement and descending control (Horak 2006). Adults with executive dysfunction have an altered gait pattern and are more at risk of falling (Kearney, Harwood et al. 2013, Muir, Beauchet et al. 2013). The relationship between gait pattern and cognition is one component of the increased rate of falls experienced by these patients. People with dementia have more 'conventional' falls risk factors than people of similar age without dementia (Shaw 2007). They also have dementiaspecific risk factors including: type and severity of dementia, specific cognitive and gait deficits, behavioural disturbances, psychotropic and cardiovascular drugs (Harlein, Dassen et al. 2009, Taylor, Ketels et al. 2012, Taylor, Delbaere et al. 2014).

Current guidelines recommend that falls prevention programmes consist of multifactorial assessment and intervention including; strength and balance retraining, home hazard assessment and intervention, vision assessment and referral, and medication review with modification/withdraw (NICE 2013). There have been many literature reviews on the effectiveness of falls interventions in older adults (Cameron, Gillespie et al. 2012, Gillespie, Robertson et al. 2012). Few have taken into account people with cognitive impairment (Shaw 2007) and there are no established or published fall prevention programmes which attempt to address cognitive impairment, although it is recognised that this should be addressed (SegevJacubovski, Herman et al. 2011).

A number of reviews have investigated falls interventions in various cognitively impaired populations (Shaw 2007, Winter, Watt et al. 2013, Guo, Tsai et al. 2014). Meta-analysis of falls prevention programmes in adults with a cognitive impairment has previously been undertaken (Guo, Tsai et al. 2014). This review included studies with mixed populations, including all degrees of severity, and institutionalised and non-institutionalised participants, making it difficult to infer which patient population benefits from the intervention and distorting clinical recommendations. In comparison there have been many published reviews concerned with falls interventions in older populations with clear endorsements for treatment content and duration (Sherrington, Tiedemann et al. 2011) within specific patient groups (Cameron, Gillespie et al. 2012, Gillespie, Robertson et al. 2012).

The extent to which studies of falls prevention programmes have involved/included cognitively impaired populations needs clearly identifying and reporting. Clarity on types of interventions used would assist clinical decision making. Due to the number of reviews within this topic area a review of reviews is warranted, providing a synopsis of the evidence of falls prevention interventions for older adults with cognitive impairment. Therefore, the research question for this review was developed and asks 'what are the findings of the reviews on falls prevention interventions for older adults with a cognitive impairment?' 


\section{Methods}

The primary purpose of this synthesis was to collate and describe previous literature reviews investigating interventions to reduce falls in adults with cognitive impairment, providing the reader with a clear summary of the evidence in this area to date. A review of review method (Grant and Booth 2009) was utilised to summarise the review literature considering the number of reviews already published in this field.

The electronic databases, MEDLINE, EMBASE, AMED, CINAHL, and the Cochrane electronic library, were searched using the terms 'falls', 'rehabilitation', 'falls prevention', 'interventions', 'cognitive impairment', 'dementia', and 'Alzheimer's disease'. Reference lists of retrieved studies were searched manually and the source of all included material is documented within Figure 1. The titles and abstracts of identified studies were read and matched against the inclusion criteria.

Inclusion criteria were that the reviews; must be available in English, report a literature search or synthesis method, include an adult population with a cognitive impairment recognised through cognitive testing (e.g. Mini Mental State Examination) or diagnosis (e.g. Dementia, Alzheimer's disease), and investigate an intervention whose primary aim was to reduce falls. Reviews were excluded if they; were inaccessible to the author (i.e. non-English language), did not include falls as an outcome or intervention of focus, used proxy measures for falls (i.e. fractures, balance), only used drugs as an intervention, or did not study a population with a cognitive impairment. For inclusivity reviews with mixed populations (those with and without cognitive impairment) were included. Due to the number of reviews identified, a further exclusion criterion of reviews published before 2000 was introduced to ensure identification of recent evidence and capture of material published prior to those dates (Smith, Devane et al. 2011). Reviews involving other neurological diagnosis (e.g. stroke, multiple sclerosis) as the cause for cognitive impairment were also excluded due to the likely impact of physical symptoms on falls risk in those populations. Search criteria were purposefully broad as mixed population and interventions are common within this field of research. The first author completed the search and all included papers were reviewed for inclusion and quality appraised independently by two reviewers (VB and VH); any discrepancies were discussed with the third reviewer. The included reviews were critiqued for quality independently by two reviewers (VB and VH) using the Joanna Briggs Institute (JBI) Critical Appraisal Checklist for Research Synthesis (JoannaBriggs-Institute 2014). This quality measure was used as recommended within the JBI: Methodology for Umbrella Reviews (2014) and rated the inclusion of topics such as review question, inclusion criteria, search strategy, critical appraisal and data extraction methods. Due to variety of review methods (i.e. narrative, meta-analysis) a quality measure was indicated to provide clarity on how the reviews synthesised material and therefore achieved their results and recommendations. Data involving 
participant details, number of studies included, intervention types, results and conclusions, and effect sizes were extracted.

\section{Results}

The search process identified seven reviews to be included. Figure 1 demonstrates the number of reviews identified at each search stage. On occasion the same study was identified from the different electronic databases and is identified as 'repeats' within Figure 1. Reasons for exclusion of reviews at full text stage are provided.

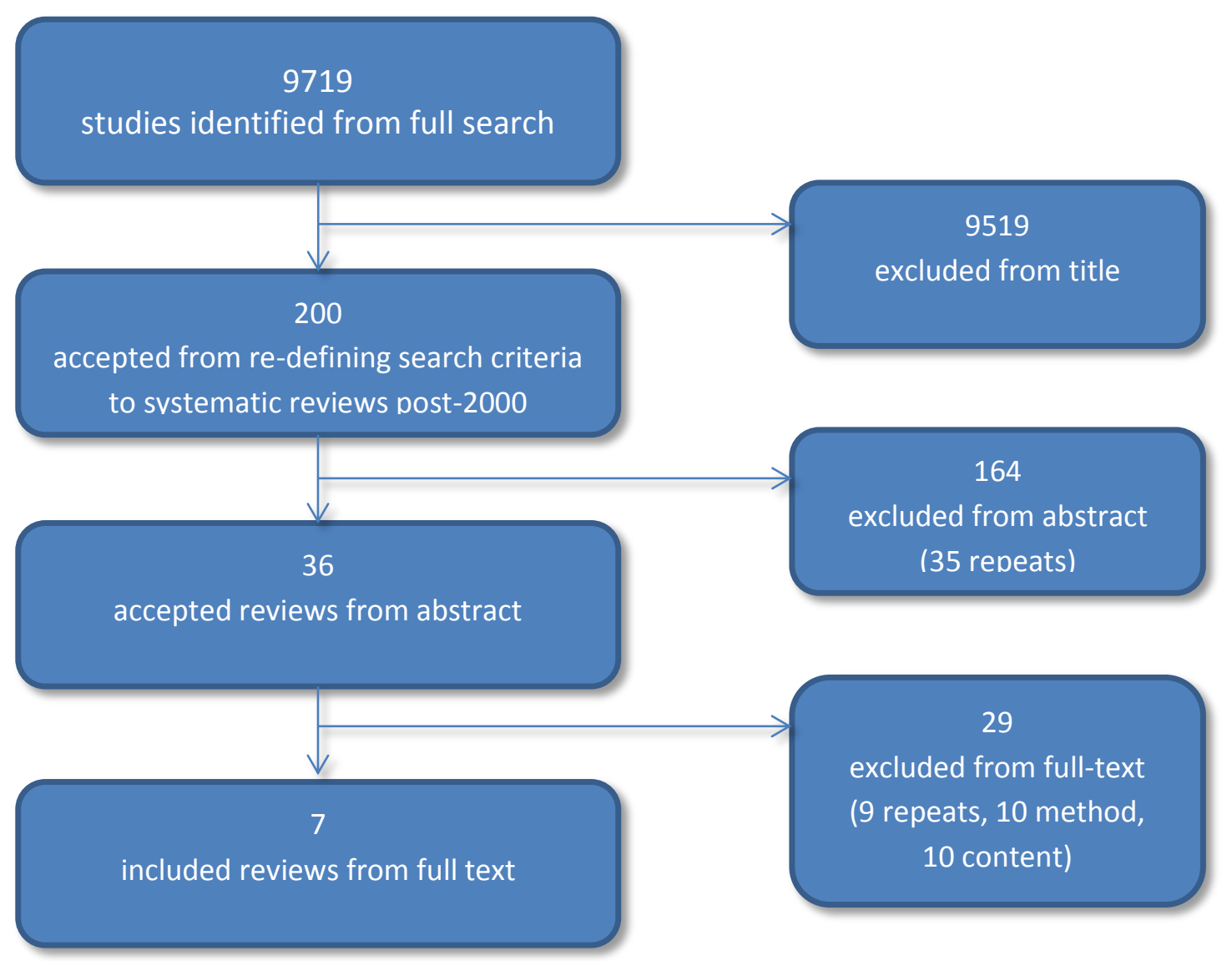

Figure 1: Flowchart illustrating reviews identified.

Only one review included a homogenous, cognitively impaired population (Tilly and Reed 2006). The other six reviews included mixed populations of adults with and without cognitive impairment (Oliver, Connelly et al. 2007, Jensen and Padilla 2011, Cameron, Gillespie et al. 2012, Gillespie, Robertson et al. 2012, Winter, Watt et al. 2013, Guo, Tsai et al. 2014). Table 1 presents the population, outcomes and summaries from the included reviews. 


\begin{tabular}{|c|c|c|c|c|}
\hline $\begin{array}{l}\text { Review Authors and } \\
\text { Method }\end{array}$ & $\begin{array}{l}\text { Number of included } \\
\text { studies; Relevant to } \\
\text { dementia/Cl, Total } \\
\text { number of studies } \\
\text { in review }\end{array}$ & $\begin{array}{l}\text { Population, } \\
\text { Prevalence of } \\
\text { dementia and Setting }\end{array}$ & Outcome Measures & Summary of findings \\
\hline \multicolumn{5}{|c|}{ Cognitively impaired populations - dementia } \\
\hline $\begin{array}{l}\text { Tilly and Reed } \\
\text { (2006) } \\
\text { Systematic review } \\
\text { No meta-analysis }\end{array}$ & $\begin{array}{l}\text { Population relevant } \\
\text { studies } n=11\end{array}$ & $\begin{array}{l}\text { Persons with } \\
\text { dementia. } \\
\text { Long-term care } \\
\text { settings. }\end{array}$ & $\begin{array}{l}\text { 1. Falls } \\
\text { 2. Unsafe } \\
\text { wandering } \\
\text { 3. Use of physical } \\
\text { restraints }\end{array}$ & $\begin{array}{l}\text { Most success in falls prevention with } \\
\text { individually-tailored interventions. } \\
\text { Identifying causes of falls and individual's } \\
\text { abilities, in combination with both fall } \\
\text { prevention and injury reduction, reduces falls } \\
\text { and fractures. } \\
\text { Single interventions or uniform approach had } \\
\text { generally unsuccessful results. } \\
\text { Use of physical restraints is not effective in } \\
\text { addressing falls or reducing wandering. } \\
\text { Little evidence exists on interventions related } \\
\text { to wandering. }\end{array}$ \\
\hline \multicolumn{5}{|c|}{ Mixed populations - with and without dementia or cognitive impairment } \\
\hline Oliver et al (2007) & $\begin{array}{l}\text { Population relevant } \\
\text { studies } n=7\end{array}$ & $\begin{array}{l}\text { Older persons } \\
\text { resident in care. }\end{array}$ & $\begin{array}{l}\text { 1. Rate ratios for } \\
\text { falls }\end{array}$ & $\begin{array}{l}\text { Multifaceted interventions in hospital had a } \\
\text { modest effect at reducing rates of falls. Hip }\end{array}$ \\
\hline
\end{tabular}




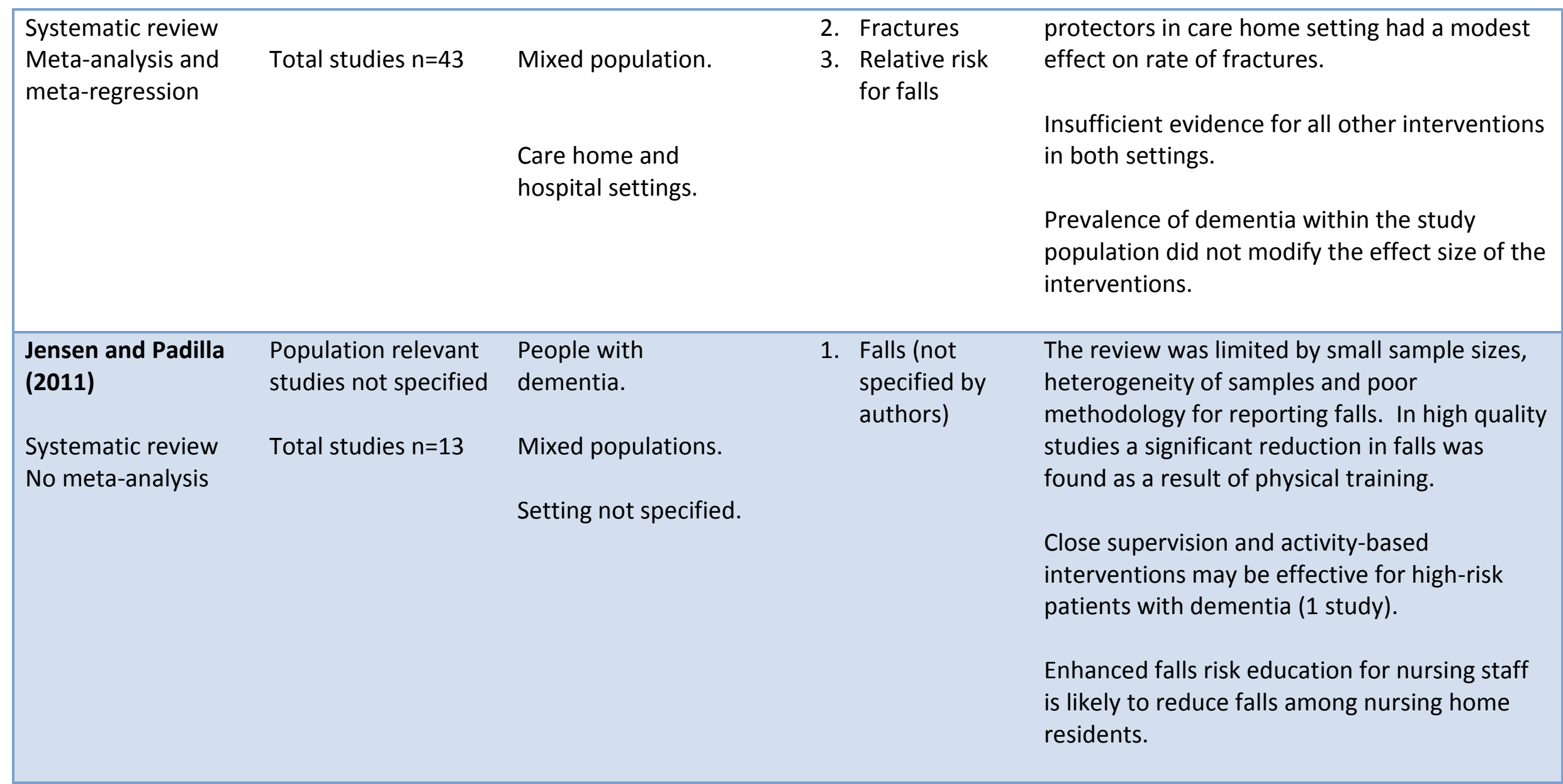




\begin{tabular}{|c|c|c|c|c|}
\hline $\begin{array}{l}\text { Cameron et al } \\
\text { (2012) } \\
\text { Cochrane Review } \\
\text { Meta-analysis }\end{array}$ & $\begin{array}{l}\text { Population relevant } \\
\text { studies } n=7 \\
\text { Total studies } n=60\end{array}$ & $\begin{array}{l}\text { Older people. } \\
\text { Mixed populations. } \\
\text { Care facilities and } \\
\text { hospitals only. }\end{array}$ & $\begin{array}{l}\text { 1. Rate of falls } \\
\text { 2. Number of } \\
\text { fallers }\end{array}$ & $\begin{array}{l}\text { More studies were conducted in care homes } \\
\text { than in hospitals. } \\
\text { Cognitive scoring did not affect the treatment } \\
\text { effect in multifactorial interventions during } \\
\text { sub-group analysis. } \\
\text { Sub-group analysis indicates that exercise as a } \\
\text { single intervention does not reduce falls in frail } \\
\text { elderly in hospital or care facilities but results } \\
\text { were inconsistent between studies. } \\
\text { Evidence for multifactorial fall prevention } \\
\text { interventions in care facilities and hospitals is } \\
\text { inconsistent, dependent upon the patient } \\
\text { group, individual ability, setting and staffing } \\
\text { delivering. Overall, the rate of falls and risk of } \\
\text { falling suggest possible benefits, but this is } \\
\text { inconclusive. }\end{array}$ \\
\hline $\begin{array}{l}\text { Gillespie et al } \\
\text { (2012) } \\
\text { Cochrane Review } \\
\text { Meta-analysis }\end{array}$ & $\begin{array}{l}\text { Population relevant } \\
\text { studies } n=67 \\
\text { Total studies } n=156\end{array}$ & $\begin{array}{l}\text { Older people. } \\
\text { Mixed populations. } \\
\text { Community-dwelling } \\
\text { only. }\end{array}$ & $\begin{array}{l}\text { 1. Rate of falls } \\
\text { 2. Number of } \\
\text { fallers }\end{array}$ & $\begin{array}{l}\text { The most common interventions were exercise } \\
\text { as a single intervention or multifactorial } \\
\text { interventions. Exercise (individualised or } \\
\text { group), home safety (when delivered by an OT) } \\
\text { and multifactorial assessment and individually } \\
\text { based interventions demonstrated } \\
\text { effectiveness at reducing falls. }\end{array}$ \\
\hline
\end{tabular}




\begin{tabular}{|c|c|c|c|c|}
\hline & & & & $\begin{array}{l}\text { Vitamin D supplementation does not appear to } \\
\text { reduce falls unless Vitamin D levels are low. } \\
\text { Only one trial had a specific population with } \\
\text { Alzheimer's disease. This investigated vitamin } \\
\text { and calcium intervention and found no } \\
\text { significant reduction in the proportion of fallers } \\
\text { but a reduction in risk of fracture. }\end{array}$ \\
\hline $\begin{array}{l}\text { Guo et al (2014) } \\
\text { Systematic review } \\
\text { Exploratory meta- } \\
\text { analysis }\end{array}$ & $\begin{array}{l}\text { Population relevant } \\
\text { studies } n=12 \\
\text { Total studies } n=111\end{array}$ & $\begin{array}{l}\text { Older adults. } \\
\text { Mixed populations } \\
\text { (with and without } \\
\text { cognitive } \\
\text { impairment). }\end{array}$ & 1. Risk of falls & $\begin{array}{l}\text { For adults with cognitive impairments: } \\
\text { Single exercise intervention was associated } \\
\text { with a positive effect in community setting } \\
\text { (one trial results). } \\
\text { In an institutionalised setting, positive effects }\end{array}$ \\
\hline
\end{tabular}


Community and

institutionalised

setting. were found from combinations of multiple and multifactorial interventions.

Exercise and education have the potential to reduce falls.

Table 1: Details of the review method, population of interest, outcomes and summary of findings from included reviews. 
The quality appraisal checklist (Joanna-Briggs-Institute 2014) scores are presented in Table 2. There were three reviews which scored the maximum (score=11) on the checklist, two of which were Cochrane Collaboration reviews (Cameron, Gillespie et al. 2012, Gillespie, Robertson et al. 2012). The two reviews which scored the lowest (score $=4$ ) included the oldest and was hindered by poor reporting of method and rigour (Tilly and Reed 2006). The other was a continuation from a review series, and therefore did not report the search method in detail and presented the results in a narrative description (Jensen and Padilla 2011). All but one review had appropriate inclusion criteria, including randomised or quasi-experimental controlled trials. Guo, Tsai et al. (2014) specifically included only interventions deemed effective in the literature, potentially resulting in reporting and publication bias. Four reviews completed meta-analysis (Oliver, Connelly et al. 2007, Cameron, Gillespie et al. 2012, Gillespie, Robertson et al. 2012, Guo, Tsai et al. 2014).

\begin{tabular}{|c|c|}
\hline $\begin{array}{c}\text { Included reviews } \\
\text { (2006) }\end{array}$ & $\begin{array}{c}\text { Total quality appraisal } \\
\text { checklist score (max=11) }\end{array}$ \\
\hline $\begin{array}{c}\text { Oliver et al } \\
\text { (2007) }\end{array}$ & 4 \\
\hline $\begin{array}{c}\text { Jensen and Padilla } \\
\text { (2011) }\end{array}$ & 9 \\
\hline $\begin{array}{c}\text { Cameron et al } \\
\text { (2012) }\end{array}$ & 11 \\
\hline $\begin{array}{c}\text { Gillespie } \text { et al } \\
\text { (2012) }\end{array}$ & 11 \\
\hline $\begin{array}{c}\text { Winter } \text { et al } \\
\text { (2013) }\end{array}$ & 11 \\
\hline $\begin{array}{c}\text { Guo et al } \\
\text { (2014) }\end{array}$ & 7 \\
\hline
\end{tabular}

Table 2: Total critical appraisal results for included studies using the JBI Checklist for Systematic Reviews and Research Synthesis

The different falls interventions reported within the included reviews are summarised and tabulated within Table 3. Exercise, multifactorial and multiple interventions were the most frequently reported. No intervention had a consistent, significant reduction in falls across all included reviews. Seventeen different 
individual interventions were documented. Most $(n=13)$ had fewer than 10 evaluation studies reported (see Table 3).

Exercise was the most frequent single intervention included in every review ( $n=91$ studies). The reported effect of exercise on falls was mixed, with only two reviews reporting significant reduction in falls following exercise ((Gillespie, Robertson et al. 2012) reported reduced rate of falls rate ratio $0.7195 \% \mathrm{Cl} 0.63$ to 0.82 and reduced risk of falls risk ratio $0.8595 \% \mathrm{Cl} 0.76$ to 0.96; (Guo, Tsai et al. 2014) reported reduced rate of falls odds ratio $0.7895 \% \mathrm{Cl} 0.66$ to 0.94$)$. Positive results were reported in another 2 reviews but were not statistically significant in their effect. When the effect of exercise was reviewed according to location, findings were mixed, both between and within reviews. Cameron, Gillespie et al. (2012) reported a significant effect of exercise within a hospital setting, based on two papers, but reported no effect within care homes based on 13 study results. Both reviews reporting significant results for exercise were within non-institutionalised participant settings (Gillespie, Robertson et al. 2012, Guo, Tsai et al. 2014). Heterogeneity from meta-analysis was reported within one review (Cameron, Gillespie et al. 2012) and differed between care homes $\left(I^{2}=70 \%\right)$ and hospital $\left(I^{2}=0 \%\right)$ studies.

Multifactorial interventions were frequently reported, with 83 studies included within six reviews. There was no consensus as to whether multifactorial interventions reduced falls, with most of the reviews $(n=4)$ reporting positive but not statistically significant results. Heterogeneity from meta-analysis was high for rate of falls across the studies in the three reviews which reported this (i.e. $l^{2}=85 \%$ from Gillespie, Robertson et al. 2012). There was slightly less heterogeneity apparent in studies completed in hospital $\left(l^{2}=59 \%\right.$ Cameron, Gillespie et al. $2012 ; l^{2}=80 \%$ Oliver, Connelly et al. 2007) versus within a care home $\left(I^{2}=84 \%\right.$ Cameron, Gillespie et al. 2012; $l^{2}=87 \%$ Oliver, Connelly et al. 2007).

Multiple interventions were classified as combinations of single interventions, completed either simultaneously or consecutively. Multiple interventions were documented in 30 individual studies across four reviews. There were no significant effects on falls from multiple interventions with three reviews reporting their results as mixed (Tilly and Reed 2006, Cameron, Gillespie et al. 2012, Gillespie, Robertson et al. 2012). Heterogeneity was not reported for the trials of multiple interventions in any of the published reviews.

Only one review commented on how falls were defined among their included studies as a determinant for inclusion (Gillespie, Robertson et al. 2012). Prospective daily calendars returned on a monthly basis for duration of follow-up were the preferred method reported by Gillespie, Robertson et al. (2012) (Lamb, Jørstad-Stein et al. 2005). 


\begin{tabular}{|c|c|c|c|}
\hline Interventions & $\begin{array}{l}\text { Number of } \\
\text { reviews }\end{array}$ & $\begin{array}{c}\text { Number of studies (total } \\
\text { number of participants if } \\
\text { given) }\end{array}$ & $\begin{array}{l}\text { Findings } \\
\text { (number of reviews with that conclusion) }\end{array}$ \\
\hline Exercise & 7 & 91 & $\begin{array}{l}\text { Significant reduction in falls (2), Positive (2), Mixed (1), No } \\
\text { effect ( } 2 \text { ) }\end{array}$ \\
\hline Multifactorial interventions & 6 & 83 & $\begin{array}{l}\text { Positive but inconclusive reduction in falls (4), Mixed (1), } \\
\text { Unclear (1) }\end{array}$ \\
\hline Multiple interventions & 4 & 30 & Positive but inconclusive reduction in falls (1), Mixed (3) \\
\hline Medication & 3 & 22 & $\begin{array}{l}\text { Positive but inconclusive reduction in falls (2), Inconsistent } \\
\text { (1) }\end{array}$ \\
\hline Hip protectors & 3 & 13 & Reduction in fracture rate (1), No effect (2) \\
\hline Staff training & 2 & 13 & Positive but inconclusive reduction in falls (1), No effect (1) \\
\hline Home assessment & 2 & 11 & Positive but inconclusive reduction in falls (1), No effect (1) \\
\hline $\begin{array}{l}\text { Assistive technology (vision, footwear, aids, } \\
\text { fall alarms) }\end{array}$ & 3 & 10 & Significant reduction in falls (1), Mixed (1), No effect (1) \\
\hline Education & 4 & 9 & $\begin{array}{l}\text { Significant reduction in falls (1), Inconclusive (1), No effect } \\
(2)\end{array}$ \\
\hline Vitamin supplement (D, Calcium or both) & 2 & 8 & Significant reduction in falls (1), No effect (1) \\
\hline Surgery & 1 & 5 & Positive but inconclusive reduction in falls (1) \\
\hline Removal of physical restraint & 1 & 5 & Unclear effect on falls (1) \\
\hline Psychological/Cognitive behavioural group & 2 & 3 & Significant reduction in falls (1), No effect (1) \\
\hline Fluid or nutritional therapy & 1 & 3 & No effect on falls (1) \\
\hline Monitoring patch & 2 & 2 & Reduction in falls (1), No effect (1) \\
\hline Flooring & 2 & 2 & Reduction in fracture rate (1), No effect (1) \\
\hline Health assessment & 1 & 1 & No effect on falls (1) \\
\hline Aromatherapy patch & 1 & 1 & Positive but inconclusive reduction in falls (1) \\
\hline Sunlight exposure & 1 & 1 & No effect on falls (1) \\
\hline
\end{tabular}

Table 3: Tabulation of included interventions, reporting the number of reviews, number of studies and results of the reviews thereof. 


\section{Discussion}

\section{Summary of Falls Interventions}

Interventions to prevent or reduce falls in healthy older adults are well documented and well evidenced (Sherrington, Tiedemann et al. 2011). Studies solely trialling interventions for adults with dementia and cognitive impairments are sparse in comparison. Only one review reported interventions trialled specifically in adults with cognitive impairment. Exercise and multifactorial interventions are most frequently reported within adults with and without a cognitive impairment, both in a community, residential care and hospital setting. None of the reported interventions demonstrated a consistent, significant reduction in falls across all including reviews. Results varied between reviews and between settings. Generally, exercise demonstrated a positive impact in community populations with less effect in a care home or institutional setting. Multifactorial interventions provided more consistently positive results across all settings but neither multifactorial nor multiple interventions provided any statistically significant effects on falls. Nineteen types of interventions were reported across all the included reviews, with most $(n=13)$ having $<10$ studies to support their findings.

\section{Quality of Reviews Summary}

This synthesis aimed to summarise reviews on falls interventions for adults with a cognitive impairment. The number of search results ( $n=200$ at abstract level) identifies that there is considerable published material on falls prevention. However, high quality, homogenous sample reviews involving interventions to reduce falls in adults with cognitive impairment are noticeably absent.

Many reviews were excluded from this paper due to; a lack of systematic search or analysis method, heterogeneity of sample populations, or interventions which did not aim to effect or reduce falls. The quality of the included reviews varied considerably (quality score range 4-11/11, 11 being good). Completion of sub-group analysis according to cognitive ability or level was inconsistent. Only two of the included reviews synthesised evidence from specific populations with dementia (Cameron, Gillespie et al. 2012, Guo, Tsai et al. 2014). The quality of the reviews must be considered in relation to findings presented and collated. The three highest quality reviews (Cameron, Gillespie et al. 2012, Gillespie, Robertson et al. 2012, Winter, Watt et al. 2013) included the greatest number of intervention studies and were able to report statistically significant findings for relevant interventions. However, they were unable to subgroup or specify for a cognitively impaired population. The two lowest quality scoring reviews failed to provide clear conclusions from their synthesises (Tilly and Reed 2006, Jensen and Padilla 2011).

Considering the narrative nature of result reporting in the many of the reviews, it is difficult to draw conclusive or clinically relevant recommendations. These conclusions reflect the paucity of published evidence of interventions involving adults with cognitive impairment 


\section{Limitations}

There are a number of limitations in this review. Firstly, a 'review of reviews' methodology provided a broad tool to describe the evidence base, but allowing this heterogeneity made pooling results difficult. Cross-reporting of studies was a risk, particularly in such a specific population with limited number of published trials.

Secondly, every attempt was made by the authors to search and include all relevant material, but some reviews may not have been found and therefore not included. This review wanted to identify falls interventions, but there are many proxy measures of falls, which for reasons of reproducibility and manageability were not included. For example, balance is associated with falls risk, but reviews which specifically used this as an intervention or focus of the review have not been included for the reasons stated.

Thirdly, the definition of cognitive impairment varies across disciplines and diagnosis. Appropriate search terms were used but it is possible not all relevant material was identified, depending upon key words. This will reflect the difficulty the reviews find when searching within this field. Some reviews of other neurological diagnosis, such as stroke or Parkinson's disease, were identified. Despite these reviews yielding useful information regarding falls interventions for those populations, these were excluded to maintain some specificity to the conclusions.

Finally, categorisation of interventions varies (e.g. discrepancies in exercise classification) leading to differing meta-analyses results and therefore differing conclusions. Exercise itself varies (e.g. Aerobic, resistance, balance training) which may have differing effects on falls risk (Power and Clifford 2013). Summarising interventions only used within cognitively impaired samples was not possible, due to paucity of source material. Not all intervention outcome measures were suitable for meta-analysis and reviews produced both narrative and statistical results from their search, i.e. Cameron, Gillespie et al. (2012). The diversity and variability of interventions within the falls literature evidence base is considerable. When collating review material, the endeavour of the research community to make each intervention novel and interesting to gain research funding becomes more evident, when the sheer numbers of single intervention trials are collated as shown within this review. Surfing this wave of innovation in turn makes it difficult to synthesise results from homogenous samples and interventions, and challenging to draw empirically derived conclusions on effectiveness.

\section{Applicability of findings}

Firm clinical recommendations cannot be made from results of the included reviews. Interestingly, sub-group analysis conducted within one review (Cameron, Gillespie et al. 2012) identified no difference in treatment effect according to cognitive scores. Considering the lack of evidence for falls interventions in adults with a cognitive impairment, it has been suggested that standard interventions are used (Sherrington, Tiedemann et al. 2011). However, the differences in risk factors for the falls in adults with a cognitive impairment are well documented (Shaw 2007, Taylor, Ketels et al. 2012, Whitney, Close et al. 2012, Taylor, Delbaere et al. 2014). 
The number of trials investigating adults with cognitive impairment is increasing. Studies have recently and are continuously being published (Gillette-Guyonnet, Andrieu et al. 2009, Kivipelto, Solomon et al. 2013, Pitkala, Poysti et al. 2013, Wesson, Clemson et al. 2013), none of which will have been included in the reviews reported in this paper.

\section{Future work}

All of the included reviews advocated the need for further, larger scaled trials involving adults with cognitive impairment. There are significant gaps in the evidence base regarding interventions to reduce falls in older adults with a cognitive impairment. The development of innovative, specific interventions to reduce falls in persons with a cognitive impairment is required. More detailed, quantitative reporting of the effects of these interventions and differences according to cognitive ability and setting (i.e. community, institutionalised) in the sample population would improve the synthesis of these studies into higher quality reviews. Stratification of intervention effects according to cognitive impairment levels, location, frequency and intensity would also be a valuable progression of research within this area. However, this is reliant on recruitment of a homogenous population to gain sufficient power to determine efficacy.

\section{Conclusions}

Evidence for falls prevention interventions for adults with a cognitive impairment is varied, provides no clear findings and limited clinical recommendations for treatment. Review materials in this area reflect the published research. In comparison to falls interventions for healthy older populations, both primary and synthesis studies are lacking in quality and number. Promising results are emerging but are hampered by heterogeneous sample populations and settings. At this time clinical recommendations cannot be made, but this is a developing evidence base and clear reporting of quantitative findings of falls and cognitive ability of the sample will encourage clearer synthesis.

\section{References}

Alzheimer's-Society (2014). Dementia 2014: Opportunity for change. https://s3.amazonaws.com/14078_Alzheimers_Interactive_Infographic/pdf/as_downlo adable_infographics.pdf. 2014.

Cameron, I. D., L. D. Gillespie, M. C. Robertson, G. R. Murray, K. D. Hill, R. G. Cumming and N. Kerse (2012). "Interventions for preventing falls in older people in care facilities and hospitals." Cochrane Database Syst Rev 12.

Craig, J., A. Murray, S. Mitchell, S. Clark, L. Saunders and L. Burleigh (2013). "The high cost to health and social care of managing falls in older adults living in the community in Scotland." Scottish medical journal 58(4): 198-203. 
Delbaere, K., N. A. Kochan, J. C. Close, J. C. Menant, D. L. Sturnieks, H. Brodaty, P. S. Sachdev and S. R. Lord (2012). "Mild cognitive impairment as a predictor of falls in community-dwelling older people." The American Journal of Geriatric Psychiatry 20(10): 845-853.

Dening, T. and A. Thomas (2013). Oxford Textbook of Old Age Psychiatry, OUP Oxford.

Gillespie, L. D., M. C. Robertson, W. J. Gillespie, C. Sherrington, S. Gates, L. M. Clemson and S. E. Lamb (2012). "Interventions for preventing falls in older people living in the community." Cochrane Database Syst Rev 9(11).

Gillespie, L. D., M. C. Robertson, W. J. Gillespie, C. Sherrington, S. Gates, L. M. Clemson and S. E. Lamb (2012). "Interventions for preventing falls in older people living in the community." Cochrane Database Syst Rev 9: CD007146.

Gillette-Guyonnet, S., S. Andrieu, T. Dantoine, J. F. Dartigues, J. Touchon and B. Vellas (2009). "Commentary on "A roadmap for the prevention of dementia II. Leon Thal Symposium 2008." The Multidomain Alzheimer Preventive Trial (MAPT): a new approach to the prevention of Alzheimer's disease." Alzheimer's \& dementia : the journal of the Alzheimer's Association 5(2): 114-121.

Grant, M. J. and A. Booth (2009). "A typology of reviews: an analysis of 14 review types and associated methodologies." Health Information \& Libraries Journal 26(2): 91-108.

Guo, J. L., Y. Y. Tsai, J. Y. Liao, H. M. Tu and C. M. Huang (2014). "Interventions to reduce the number of falls among older adults with/without cognitive impairment: an exploratory meta-analysis." International journal of geriatric psychiatry 29(7): 661669.

Harlein, J., T. Dassen, R. J. Halfens and C. Heinze (2009). "Fall risk factors in older people with dementia or cognitive impairment: a systematic review." Journal of advanced nursing 65(5): 922-933.

Horak, F. B. (2006). "Postural orientation and equilibrium: what do we need to know about neural control of balance to prevent falls?" Age and ageing 35 Suppl 2: ii7-ii11. Jensen, L. E. and R. Padilla (2011). "Effectiveness of Interventions to Prevent Falls in People With Alzheimer's Disease and Related Dementias." American Journal of Occupational Therapy 65(5): 532-540.

Joanna-Briggs-Institute (2014). "Joanna Briggs Institute Reviewers' Manual: Methodology for JBI Umbrella Reviews." Adelaide: The Joanna Briggs Institute.

Kearney, F. C., R. H. Harwood, J. R. Gladman, N. Lincoln and T. Masud (2013). "The relationship between executive function and falls and gait abnormalities in older adults: a systematic review." Dementia and geriatric cognitive disorders 36(1-2): 2035 .

Kivipelto, M., A. Solomon, S. Ahtiluoto, T. Ngandu, J. Lehtisalo, R. Antikainen, L. Bäckman, T. Hänninen, A. Jula and T. Laatikainen (2013). "The Finnish Geriatric Intervention Study to prevent cognitive impairment and disability (FINGER): study design and progress." Alzheimer's \& Dementia 9(6): 657-665.

Lamb, S. E., E. C. Jørstad-Stein, K. Hauer and C. Becker (2005). "Development of a common outcome data set for fall injury prevention trials: the Prevention of Falls Network Europe consensus." Journal of the American Geriatrics Society 53(9): 16181622.

Lord, S. R., C. Sherrington, H. B. Menz and J. C. Close (2007). Falls in older people: risk factors and strategies for prevention, Cambridge University Press.

Muir, S. W., O. Beauchet, M. Montero-Odasso, C. Annweiler, B. Fantino and M. Speechley (2013). "Association of executive function impairment, history of falls and 
physical performance in older adults: A cross-sectional population-based study in Eastern France." The journal of nutrition, health \& aging 17(8): 661-665.

NICE. (2013). "Clinical Guideline 161. Falls: assessment and prevention of falls in older people " Retrieved 19/12/2014.

Oliver, D., J. B. Connelly, C. R. Victor, F. E. Shaw, A. Whitehead, Y. Genc, A. Vanoli, F. C. Martin and M. A. Gosney (2007). "Strategies to prevent falls and fractures in hospitals and care homes and effect of cognitive impairment: systematic review and meta-analyses." BMJ 334(7584): 82.

Pitkala, K. H., M. M. Poysti, M. L. Laakkonen, R. S. Tilvis, N. Savikko, H. Kautiainen and T. E. Strandberg (2013). "Effects of the Finnish Alzheimer disease exercise trial (FINALEX): a randomized controlled trial." JAMA internal medicine 173(10): 894-901.

Power, V. and A. M. Clifford (2013). "Characteristics of optimum falls prevention exercise programmes for community-dwelling older adults using the FITT principle." European Review of Aging and Physical Activity 10(2): 95-106.

Segev-Jacubovski, O., T. Herman, G. Yogev-Seligmann, A. Mirelman, N. Giladi and J. M. Hausdorff (2011). "The interplay between gait, falls and cognition: can cognitive therapy reduce fall risk?" Expert review of neurotherapeutics 11(7): 10571075.

Shaw, F. E. (2007). "Prevention of falls in older people with dementia." Journal of neural transmission 114(10): 1259-1264.

Shaw, F. E., J. Bond, D. A. Richardson, P. Dawson, I. N. Steen, I. G. McKeith and R. A. Kenny (2003). "Multifactorial intervention after a fall in older people with cognitive impairment and dementia presenting to the accident and emergency department: randomised controlled trial." Bmj 326(7380): 73.

Sherrington, C., A. Tiedemann, N. Fairhall, J. C. Close and S. R. Lord (2011). "Exercise to prevent falls in older adults: an updated meta-analysis and best practice recommendations." New South Wales public health bulletin 22(4): 78-83.

Smith, V., D. Devane, C. M. Begley and M. Clarke (2011). "Methodology in conducting a systematic review of systematic reviews of healthcare interventions." BMC medical research methodology 11(1): 15.

Taylor, M. E., K. Delbaere, S. R. Lord, A. S. Mikolaizak, H. Brodaty and J. C. Close (2014). "Neuropsychological, physical, and functional mobility measures associated with falls in cognitively impaired older adults." The journals of gerontology. Series A, Biological sciences and medical sciences 69(8): 987-995.

Taylor, M. E., M. M. Ketels, K. Delbaere, S. R. Lord, A. S. Mikolaizak and J. C. Close (2012). "Gait impairment and falls in cognitively impaired older adults: an explanatory model of sensorimotor and neuropsychological mediators." Age and ageing 41(5): 665-669.

Tilly, J. and P. Reed (2006). "Falls, wandering, and physical restraints: interventions for residents with dementia in assisted living and nursing homes." Alzheimer's Association. Available at: http://www. alz. org/(accessed 12 February 2007).

Wesson, J., L. Clemson, H. Brodaty, S. Lord, M. Taylor, L. Gitlin and J. Close (2013). "A feasibility study and pilot randomised trial of a tailored prevention program to reduce falls in older people with mild dementia." BMC Geriatr 13: 89.

Whitney, J., J. C. Close, S. H. Jackson and S. R. Lord (2012). "Understanding risk of falls in people with cognitive impairment living in residential care." Journal of the American Medical Directors Association 13(6): 535-540. 
Winter, H., K. Watt and N. M. Peel (2013). "Falls prevention interventions for community-dwelling older persons with cognitive impairment: a systematic review." International psychogeriatrics / IPA 25(2): 215-227. 